\title{
DEATH CAN BE PROUD
}

\author{
LESTER BUTT, Ph.D. \\ JULIETTE ROTHMAN, M.S.W., Ph.D.
}

We tend to believe that legal rules and moral principles can and will provide us with clear guidelines for action in specific cases. Too often, we find that law and ethics cannot answer the questions that present themselves to us. Nowhere is this difficulty more commonly experienced than in the area of medical decisionmaking and medical ethics.

As professionals, we attempt to juggle the law, professional codes of conduct, and our own sense of moral propriety, finding that it is not always easy to resolve conflicts among them. Even if the United States Supreme Court and other state courts have said that patients have the right to refuse life-sustaining treatment, it is one thing to know that--and something else to act upon those beliefs. It is clear that patients have "rights," but issues of rationality, comprehension, and the timing of such decisions can be uncertain. What it means to respect the worth and dignity of each individual can point us in several different directions, each with its own cogent set of arguments. On some occasions, all that we can be sure of is that we are unsure. In the rehabilitation setting, these uncertainties are amplified.

Medical ethics and rehabilitation medicine challenge each other in many ways (1) (2). This case study illustrates how uncertain, difficult, and complex decisions about life-sustaining treatment can be in the rehabilitation setting, and offers some explanations of why this is so. While there is little dispute about whether a competent individual has the right to forgo life-sustaining treatment, considerable controversy surrounds the question of when it is appropriate to make this decision (3) (4) (5). How we, as rehabilitation professionals, respond to such requests reveals our sense of what it means to respect patients as persons, regardless of whether they express this wish early or long after the onset of disability. 
The challenge to the rehabilitation professional is to apply agreed-upon principles in situations where we find ourselves torn: to demonstrate respect for values and persons under conditions of uncertainty and ambivalence.

The following case is not to be taken as illustrative of the manner in which all similarly disabled people should be treated. It is one person's story. It does illustrate the difficulties of tying theory to clinical practice. We offer it precisely because of its inherently complex and controversial nature.

Daniel is twenty-one years old, and in the prime of his life. He is a senior at a prestigious university in the Northeast, where he is a premed major and an honors student. Those who know him describe him as idealistic, intense, confident, athletic, sensitive, persistent, gregarious, determined, loyal, and devoted to his family and friends. He has been interested in contemplating the universe, God, and the meaning of life. $\mathrm{He}$ is concerned about the environment and ecology, enjoys building and using his hands. His interests include swimming, bungee jumping, parasailing, lacrosse, rugby, running, weight lifting, boating, sailing, camping, and hiking. Daniel comes from a nurturing family. His father is a physician; his mother has a degree in social work, and a doctorate in philosophy. She wrote her dissertation in medical ethics, discussing quality-of-life secondary to having a chronic illness. Daniel has two sisters. The family enjoys traveling abroad together. Daniel hopes one day to practice medicine in underdeveloped countries.

On July 3, 1992, Daniel dives into a pool of water that is four feet deep and is immediately rendered a C4-5 quadriplegic. Although his injury does not cause him to lose consciousness, it does necessitate a surgical reduction and fusion. $\mathrm{He}$ is immediately placed on a methylprednisolone protocol to reduce swelling and the possibility of further cord destruction. Several days after surgery, for unknown reasons, but possibly as the result of post-surgical swelling, Daniel's paralysis ascends. During his initial acute hospitalization, he manifests the following difficulties: respiratory insufficiency requiring intubation and continuous ventilator support, neurogenic bowel and bladder, placement of a cardiac pacer to control episodes of bradycardia/asystole, three episodes of respiratory arrest that require resuscitative efforts, frequent suctioning of secretions with much accompanying discomfort, and persistent deafferent pain which he experiences as a severe burning sensation. At the request of the family and facility, a Craig Hospital physician makes a consultation- 
evaluation at the other facility. At that point, Daniel has no sensation or movement from his jawbone down. He has become a complete $\mathrm{C}-1$ quadriplegic.

While a patient in the other facility, Daniel expresses a desire to die, a not uncommon occurrence among recently injured individuals. This request generates understandable anxiety and concern on the part of his parents. Notwithstanding the physicians' willingness to honor Daniel's wish, his parents disagree. They explain to Daniel that it is far too early to make such a monumental decision, as he does not possess enough information about his prognosis and functional abilities, and does not know what constitutes a life with a disability. Therefore, they feel, he does not have enough insight to render such a decision. Daniel and his parents decide to pursue rehabilitation in order to determine his rehabilitative potential, with the understanding that, if his prognosis and potential are not satisfactory to him, his parent will accept his decision to forgo ventilator support, and advocate for him if needed.

Entering Craig Hospital, Daniel is essentially a $\mathrm{C} 1$ complete quadriplegic. The early rehabilitative plan addresses the following: evaluation of his respiratory and nutritional status, potential for vocalization, mobilization, patient and family education, equipment needs, and home modifications.

Daniel's physical condition continues to decline. A scan reveals a brain stem lesion which render his ability to swallow and eat virtually nonexistent. Additionally, aspirations preclude the use of a talking trach, thereby curtailing his ability to vocalize in a functional manner. Unfortunately, the prognosis is becoming clearer. Daniel is looking forward to life as a C-0 brain-stem quadriplegic, ventilator dependent, virtually unable to speak or swallow, susceptible to multiple infections, manifesting recurrent acute respiratory distress syndrome, and dependent upon loved ones and support systems for the most basic of care.

His parents are given this information as sensitively and supportively as possible. Many discussions ensue, especially between the parents and physicians about how certain and confident the doctors are about their clinical assessments. Later, Daniel's mother writes about this period in time:

"When, after ten-and-a-half weeks spent mostly in intensive care units, we, his parents, were informed that there was no hope for improvement in Daniel's condition, 
we began the most difficult decision-making process parents can ever undergo. Daniel had not been informed as yet. Should we ask that he be told? And, when he was told, should we offer him the choices that he was too young to know that he had? Sadly, all of my years spent considering such situations was put to this immediate and pressing use. We decided that he had to know. It was his life, and he had the right to information regarding it. We also decided that I would offer him the choices that we knew lay before him, but that he did not: to live, with all of the help, love, and resources that we could provide him, under his medical limitations; or to choose to refuse to continue on the ventilator, and thus to end his life."

Daniel is surprised to learn that he can be actively and centrally involved in the decision-making process. As is often the case when patients express the wish to forgo life-sustaining treatment, the denial of his initial request, as well as the act of discussing his condition privately with his family only, causes him to believe that he has no choice other than to accept and live with his condition. When informed of the prognosis by his physicians, and of his choices by his family, Daniel again announces his desire to be allowed to die.

Informed consent is the foundation of clinical decision-making, and promotes dialogue between patient and physician (6). Our common regard for the value of consent emanates from the root premise that every human being of adult years and sound mind has a right to determine what shall be done with his own body. In order for consent to be valid, it should be sufficiently informed, voluntary, and competent. Generally speaking, attention is centered on questions about the quality of the information upon which patients base their decisions, the presence or absence of factors that affect the volitional nature of choice, and the patient's competence to decide. Daniel's case raises interesting questions with respect to each of these factors.

Tests for determining whether a patient is competent vary considerably, revealing how difficult it can be to balance respect for personal choice with respect for individual well-being. Depending on how much emphasis we wish to place on these interests, we can require that patients who wish to be regarded as reliable arbiters of their fate establish that they can: [1] make a rational choice, [2] appreciate their situation and 
the consequences of their choice, [3] understand the information given to them, or [4] simply communicate a choice (7) (8). What we want is a choice that is authentic and insightful; what we need is a test that provides us that. What we lack is the means to eliminate ambivalence and uncertainty from this assessment. In practice we try to be sensitive to all of these features simultaneously, which causes us to struggle between respecting a patient's wishes under the circumstances, and respecting wishes that seem sensible to us. We struggle to make judgments without being judgmental, to share what we know without imposing what we believe. Just how to resolve these tensions is not easy to discern. In Daniel's case, each of the two psychologists asked to assess him concluded that he was competent to make this decision, to articulate a wish that deserved to be respected by others.

Is he sufficiently informed? Certainly he is told all that he needs to know and all that he wants to know about his future prospects. Does he know enough? Does he comprehend what he has been told? Can he? In all honesty, all anyone can tell him is what it might be like to live with his condition (9). No one can tell him what it would be like for him.

Does the fact that he can live mean that he should or must, regardless of whether he would want to? We recognize that the experience of what it is actually like to live as a person with a disability can and often does offer insight that "information" alone does not, and have even acted on this principle in many instances.

If the experience of some, even most, patients is to establish an immutable rule on decisions for all patients, other questions emerge. How much time must pass, and how many of what kind of experiences must a person with a disability have before we feel comfortable with a request to forgo life-sustaining treatment? When does "not yet" become "now" and why? What makes one decision about when it is appropriate to stop treatment demonstrably or inherently superior to another? Can we safely say that our hesitation at allowing patients to forgo life-sustaining treatment has only to do with our desire to permit them to have the time they need to adjust to being disabled, and nothing to do with our inability or unwillingness to accept their death? In "allowing" patients the time to be comfortable with disability are we simply allowing ourselves to remain uncomfortable with death? Is it the patients or the providers who cannot accept reality? Without compromising our commitment to "rehabilitate the world," to encourage and enable all persons with disabilities to be all that they can be, can we make allowance for patients who say "What's 
good for you and for them is not for me?" Is rehabilitation's agenda the patient's mandate? If discriminating judgment means anything, it means not applying concepts in a rote fashion, but rather accepting the uncertainties and ambiguities that plague clinical decisionmaking.

To suppose that choices are made free of internal and external constraints is to believe that patients can decide things independent of who they are and the ordeal in which they find themselves. This is an abstract ideal that does not reflect the realities of the clinical setting. All we can ever hope for is that patients make their decisions with as much balance as possible, and without duress, coercion, or manipulation. While we need to be concerned about whether it is the patient or his trauma that is talking, we also need to recognize that patients are not and cannot be separated from their trauma, as if the event and the person are wholly distinct. Individuals integrate experiences, including catastrophic injuries, into their lives in different and diverse ways. We can and should help patients by offering encouragement, support, and hope, all of which are provided in Daniel's case. Should we cajole, manipulate, or even coerce him to integrate this event into his life in only one way? While we promote the educational model of rehabilitation, we must be sensitive to the difference between education and indoctrination, teaching and insisting.

Should we view Daniel's choice as suicide? The simple answer to this is "no," since the cause of Daniel's death is his fatal accident, which would have killed him immediately but for the intervention of medical technology. The fact that we can attribute Daniel's death to accidental causes or say that a desire to forgo treatment is not the same as committing suicide should not cause us to stop wondering or be concerned about what motivates patients to make these choices. The question of whether such patients are or are not "suicidal" treats a complex issue too simply. After all, we know patients whose desire to die eventually yields to gratitude at being alive. Yet we also know patients whose ability to accept death and whose desire to forgo treatment persist. What we have difficulty knowing is into which group a patient who expresses a desire to die falls.

The prevention of suicide is predicated upon the assumption that suicide is a pathological event, the medicalization of what once was a criminal matter. As Lowenthal has written, "The common denominator of most explanations has a pathologic orientation, suicide being regarded as a sickness, a symptom to be treated and prevented" (10). Is the act 
necessarily pathological, or does indiscriminate suicide prevention reflect our denial of the fact that life does inflict upon some of us tragedies that we can neither eliminate or undo? Did Daniel's decision accept fate, or reject life?

One complication here is the assumption that all suicide implies a psychiatric or psychopathological disturbance, and therefore warrants a therapeutic intervention. This assumption merits examination. When clinicians know they are evaluating a "suicidal" individual, in that prior to the assessment the clinicians are so told, their diagnosis of mental illness is higher than when this knowledge is withheld (11). To the extent that suicide suggests pathology, we create a world in which the "suicidal" becomes the pathological. At worst this is a rote response, but under the best of circumstances we cannot divest our view of the "suicidal" from our view of suicide. Whether this enhances or distinguishes our ability to see the patient for who he is and to hear what he is saying is worth considering.

Here we will discuss only one component of suicidal ideation: that personal distress and/or intense affect is an indication of suicidal ideation. It is true that a suicide is rarely without intense affect, but this statement may confuse "feeling disturbed" and therefore in psychological distress, with "being disturbed" and therefore expressing a psychopathology. The first phrasing allows for the subjective experience of distress to be a reasonable reaction to a present situation, while the latter phrasing implies an inherent, internal quality of irrationality or emotional instability. In fact, the intense affect of many suicidal persons may be a quite reasonable reaction to their present life condition. Should we expect individuals who elect to forgo life-sustaining treatment to approach that decision with equanimity? Is an intense reaction to a catastrophic event normal or abnormal? Just what constitutes the normal, i.e., appropriate emotional state?

"Many self-destructive individuals have made an accurate empirical assessment of their life chances" $(11$, p. 206). Suicidal behavior is typically associated with personal distress, but to assume that the suicidal ideation results from this distress may be to confuse a covariation with a causation. The suicidal ideation and distress, for instance, may both result from a third variable. They may both follow from a loss of meaning, value, or purpose. We can help and support individuals to find meaning, but can we force them to do so? Years ago Daniel's accident would have been a tragic death. Now that medicine enables him to survive and reflect on 
that event, is he prohibited from continuing to regard it as tragic?

Szasz states, "A man's life belongs to himself" (12). Suicide prevention is interpreted from this perspective as an abridgment of individual liberty. Health care providers typically and unconditionally attempt to relieve suffering, and to protect and prolong life. To allow a suicidal patient to die is considered an irrevocable, ultimate, and tragic treatment failure. While there is nothing wrong with wishing life for people, there is something remiss with wishing people not to die. It would be difficult to defend a therapist's dogmatic adherence to patient selfdetermination and autonomy when the patient's basis for suicide was obviously irrational. On the other hand, the opposite extreme, of not allowing patient self-determination and autonomy when the desire of the patient is incompatible with one's own hopes or values, can be equally dogmatic. Here again, we find ourselves having to apply principles to cases, under conditions of uncertainty and ambiguity.

Dying may be preferable to living. If treatment is intended to relieve suffering, what if the suffering cannot be relieved and, despite all efforts, the person still found life to be intolerable and unacceptable? The reasonableness of an intentional death in light of a sustained but unacceptable existence is becoming publicly acceptable. Yet this acceptance is as ambivalent as efforts to reject it are. To the extent that public acceptance of the "right-to die" reflects the belief that no one would want to live "like that," it reflects prejudice against persons with disabilities. Yet to the extent that others resist any decision to forgo lifesustaining treatment, they imprison persons with disabilities in the view that no one would not want to live like that, which is as prejudicial. This explains why the disabilities rights movement finds something to like and something to dislike in what right-to-die and right-to-life advocates have to say.

What persons with disabilities need is a perspective that tolerates and respects the range of beliefs they hold, to know that someone is respected individually, not treated simply as a member of a group (13). Respect occurs not when others presume to know what someone would or would not want, or what it must or should be like to live "like that," but when they know and respect the individual for the person he or she is.

Granted, there are individuals who continue their lives, overcome devastating injuries, illnesses, and losses, and even excel. Their lives are inspirational. These people exemplify what can be salvaged from what appears to be a catastrophe. However, heroes typically are volunteers not 
conscripts. That some choose to persevere does not mean that all must do so. Instead of centering our scrutiny solely on the patient, we need to scrutinize ourselves as well.

The factors that might inhibit our accurate assessment of suicide include: [1] anxiety over one's own suicide potential, [2] guilt over one's own potential contribution to another's death, and [3] shame over one's inability to help a "suicidal patient." To consider death as a reasonable option is indeed threatening to one's own self and one's therapeutic identity. It is difficult to recognize that there are circumstances in which life may not be worth living and that one is powerless to rectify this fact. We may be so worried about the patient's state of mind that we may ignore our own, and miss the extent to which we project our own beliefs and values on others. Here again, we find ourselves in ambivalence, struggling to separate the observer from the observed.

These personal difficulties are compounded by professional concerns: dedication to the preservation of life, the fear of loss of patient/societal trust, fear of malpractice litigation, and values that providers introduce into the calculus of consent. They are complicated by the fact that they occur within a system that treats persons with disabilities inequitable and poorly. We cannot separate ourselves or our patients from the context within which these decisions arise.

Ultimately, the question is not whether we can or cannot, should or should not make decisions or respect wishes in cases such as Daniel's. Rather, given that these decisions arise and these choices are uttered, the question is how we should respond given that a choice must be made. The answer is as simple as it is complex: respectfully, deliberately, and judiciously.

Communication needs to be clear. Everyone who is likely to be significantly affected by the decision needs to be involved in the process by which the decision is reached. The participation of some will be more intensive and extensive than of others, but respect for all requires their participation. Good judgment depends on good facts. All that can be known and shared must be brought out and communicated with due regard for the time it takes to ascertain information and for that information to be well comprehended. This includes a thorough review of rehabilitation options and a psychological assessment of the patient. We need to make certain that we know all that can be known about: [1] the patient's diagnosis and prognosis, [2] the patient's decision-making capacity, [3] the durability of the patient's wish, [4] the presence or 
absence of any coercive influences, whether personal and/or financial, [5] the concurrence of family members, [6] the concurrence of members of the health care team, and [7] what the law requires, permits, and expects of us.

\section{DANIEL'S FINAL CHAPTER}

Daniel took control of his final days. As his mother writes, "Dan decided he wanted to say good-bye to friends and family. The nurse helped us get a phone connected and I called all his best friends: his high school buddy, the friends at the fraternity. Then I called his grandmothers, his uncle, and lastly, his sisters. To each I explained that Daniel had decided to turn off the ventilator and wanted to say good-bye. It was a very difficult thing: everyone cried and then tried to talk to Dan and he made his noises back to them....' It's my last night, Mom,' Dan mouthed, 'Will you stay here with me, and sit by my bed so that I can see you?' I did, and my husband stayed too. I watched over Dan and we spoke of many things: what death could be like, his funeral, where he would be in the cemetery, our love."

The next day his sisters called and played to him tapes of Daniel himself, recorded when he was a young child. They played to him his favorite tape, "The Fractured Fairy Tale of Little Red Riding Hood," and read the 21st Psalm. One sister was pregnant with a boy, and told him she would name the child Daniel. Daniel requested and was allowed to have, in spite of his respiratory status, his favorite drink, Strawberry Daiquiris, out of respect for the ritual of his college fraternity. Daniel and his parents together toasted Daniel's life and his future.

Mother continues:

"We asked to be alone a little while and took our prayer book and prayed with Dan. I read him his Bar Mitzvah portion, and we sang his favorite prayers. He mouthed the words with us and it seemed to me that I could hear his voice but maybe it was just my wish. I sat by his bed 
and looked from him to the clock, and the pain was so bad I felt numb. 'Are you sure, Dan,' I would ask in agony, 'Are you sure you don't want to wait a little while?' 'I'm sure, Mom,' he would mouth, 'I can't live like this."

Daniel was mildly sedated so he would not experience agonal breathing (14).

Mother again writes:

"Daniel's eyes closed. I leaned down and put my arms around him and held on tight. The doctor removed the tubing from Dan's neck, and I hugged tight and could feel the air from the vent blowing across my face. I concentrated my sole being on Dan. After a while I cried. Dan was dead."

Daniel's family carved their initials on his casket, and inscribed "We love you." His grave stone reflects words from his favorite music group, The Grateful Dead: "Standing in a shaft of light, Rising up to Paradise, I know I'm gonna shine."

Daniel's mother writes,

"In retrospect I believe that Dan really did live his life, and die, with his values and ideals intact. He lived a full, beautiful life for twenty-one years. He died the way he lived. He never whined or cried or said 'Why me?' or acted unjustly. He had an accident and dealt with it with courage and dignity. He died without fear or doubt, without wavering in his self-concept. He had death with full awareness. I am proud to have been his mother. Thank you all, each and every one, for all that you did for my son. My God bless you, and your loved ones, and give you strength in the work that you do. With sincere affection, Juliette."

Assuredly and thankfully, most individuals choose to live with disability and most thrive. However, we must demonstrate respect and 
tolerance for the minority who do not. Changing medical values and public opinion, the escalating cost of medical care, managed care, and expensive technology are altering the face of health care delivery. Our moral horizon is gray, but not grim. Certainly this is the case where bioethics and rehabilitation meet, especially where death is concerned. Categorical acceptance or rejection of requests such as Daniel's is problematic. Individual differences in our pluralistic society need be considered. To unilaterally mandate that all must conform to the values and standards of health care professionals, whatever they may be, is unjust. Only via an objective, sincere exploration with the patient and family regarding his or her request can we begin to accurately discern its potential validity and merit.

Daniel's story is neither typical nor categorical. It is one person's story, a story that illustrates how important it is to care, how difficult it can be to know what caring means, and how profoundly challenging it is to care for patients who choose a fate that awaits us all (15).

\section{REFERENCES}

1. Scofield GR. Ethical consideration in rehabilitation medicine. Archives of Physical Medicine and Rehabilitation. 1993; 74:341-46.

2. Caplan A, Callahan D, Haas J. Ethical and policy issues in rehabilitation medicine. Hastings Center Report (Special Supplement). 1987; 17(4):1-20.

3. Patterson DR, Mullen PC, McCormick TR, Hudson LD. When life support is questioned early in the care of patients with cervical-level quadriplegia. New England Journal of Medicine. 1993; 328: 506-509.

4. Maynard FM. Responding to requests for ventilator removal from patients with quadriplegia. Western Journal of Medicine. 1991; 154: 617-19.

5. Maynard FM, Ruth AS. The choice to end life as a ventilatordependent quadriplegic. Archives of Physical Medicine and Rehabilitation. 1987; 68: 862-64.

6. Appelbaum PS, Lidz CW, Meisel A. Informed Consent: Legal theory and clinical practice. New York, NY: Oxford University Press; 1987.

7. Freedman M, Suss DT, Gordon M. Assessment of competency: The role of neurobehavioral deficits. Annals of Internal Medicine. 
1991; 115: 203-208.

8. Roth LR, Meisel A, Lidz CW. Tests of competency to consent to treatment. A.M.J. Psychiatry. 1977;134: 279-84.

9. Gilgoff IS. Living with a ventilator. Western Journal of Medicine. 1991; 154: 619-22.

10. Lowental U. Suicide-the other side. The factor of reality among suicidal motivations. Archives of General Psychiatry. 1976; 33: 83842.

11. Maris RW. Pathways to suicide. Baltimore, MD.: Johns Hopkins University Press; 1981.

12. Szasz TS. The ethics of suicide. In BB Wolman, ed. Between survival and suicide. New York, N.Y.: Gardner Press; 1976.

13. Allport G. The nature of prejudice. New York, NY: AddisonWesley; 1979.

14. Schneiderman LJ, Spragg RG. Ethical decisions in discontinuing mechanical ventilation. New England Journal of Medicine. 1988; 318: 984-88.

15. Edwards M, Tolle S. Disconnecting a ventilator at the request of a patient who knows he will die: The doctor's anguish. Annals of Internal Medicine. 1992; 117: 254-56. 